\title{
A FULLY BIODEGRADABLE PLA/PBS COMPOSITE REINFORCED WITH WOOD FLOUR
}

\author{
JOANNA LUDWICZAK, ${ }^{*}$ STANISŁAW FRĄCKOWIAK, ${ }^{*}$ KAROL LELUK* and \\ BEATA HANUS-LORENZ,*** \\ *Faculty of Environmental Engineering, Wroctaw University of Science and Technology, \\ 27 Wybrzeże Wyspiańskiego Str., 50-370 Wroctaw, Poland \\ ${ }^{* *}$ Faculty of Fundamental Problems of Technology, Department of Biomedical Engineering, \\ Wroctaw University of Science and Technology, Wybrzeże Wyspiańskiego 27, \\ 50-370 Wroctaw, Poland \\ \Corresponding author: Joanna Ludwiczak, joanna.ludwiczak@pwr.edu.pl
}

Dedicated to the $70^{\text {th }}$ anniversary of the Department of Pulp and Paper, "Cristofor Simionescu" Faculty of Chemical Engineering and Environmental Protection, "Gheorghe Asachi" Technical University of Iasi

\begin{abstract}
The development rate of the biodegradable polymers market has been rising year by year, mainly due to the increasing demand of replacing non-biodegradable polymer plastics with their environment-friendly representatives. In spite of this, the contribution of biodegradable polymers on the overall plastic market is still marginal. Besides the price, their poor mechanical properties, which may not stand up to the requirements that plastics are expected to meet, are responsible for that. That is why, many biodegradable polymer blends, modified with different fillers, are under investigation. In this work, a PLA/PBS system was reinforced with wood flour and additionally modified with a chain extender. As a result, macromolecular chain extension was observed, as well as an improvement in tensile strength, whereas elasticity remained at the same level as that for the wood flour filled composite. The water absorption rate increased as a function of filler concentration. Contrary to rheological and mechanical test results, no significant influence of the chain extender was observed.
\end{abstract}

Keywords: polylactide, polybutylene succinate, wood flour, chain extender

\section{INTRODUCTION}

Environmental awareness prompts us to replace traditional polymers with biodegradable materials. A well-known biodegradable polymer is poly(lactic acid) (PLA). PLA is a thermoplastic biopolymer, which belongs to the group of aliphatic polyesters. It is obtained from renewable natural resources, such as maize meal or sugarcane. Its basic disadvantage is its high price, but also, in comparison with traditional synthetic polymers, its quite high brittleness. In order to improve its properties, it is possible to introduce modifiers, compatibilizers or fillers into the polymer matrix. ${ }^{1-9}$ Poly(butylene succinate) (PBS) is produced from succinic acid and 1,4butanediol. Due to the biodegradability and very good processing properties of PBS, in comparison with those of PLA, the creation of composites or blends of the two materials seems to be a favourable way to improve their properties, as can be observed in numerous studies. ${ }^{10-17}$ Natural fibers, which have a number of advantages, such as low price, wide availability and biodegradability, are used in order to strengthen composites. Among natural fibers, vegetable fibers contain highly polarized hydroxyl groups, which are inherently hydrophilic. ${ }^{18}$ These fibers are incompatible with hydrophobic thermoplastics, especially the synthetic ones. The moisture absorption rate of fibers is significantly high and leads to poor interfacial adhesion to the hydrophobic matrix of polymers.

Chuayjuljit et $a .^{14}$ tested the strength and thermal stability of PLA after the addition of PBS and wood flour (WF). Their research shows that, along with the increase in the content of WF, the impact strength, tensile strength, bending strength 
and thermal stability of the obtained material are reduced, while the degree of crystallinity increases slightly. It was also noted that the addition of PBS and WF does not significantly change the glass transition and melting temperature of PLA in PLA/PBS and PLA/PBS/WF materials. Other researchers ${ }^{19}$ prepared PLA/PBS composites with the addition of a chain extender. Their findings showed that the addition of PBS and of the chain extender to PLA resulted in a decrease in the tensile strength and modulus of elasticity, but it increased the elongation at break. It was also shown that the thermal stability of the composites was lower than that of the unmodified PLA.

In this work, PLA/PBS composites, with the addition of wood flour, were developed. A chain extender was used to improve the interaction between the polymers and the filler. Mechanical, rheological and thermal tests, as well as morphology analysis, were performed. Water absorption, which is an important parameter for biodegradable composites, was also determined for all the prepared materials.

\section{EXPERIMENTAL}

Materials

Polylactide (PLA) Ingeo 3052D, supplied by Nature Works LCC (USA), and polybutylene succinate (PBS) PBE 003 BB (NaturePlast, France) were used. Wood flour (WF) Lignocel C120, with particle size of 70-150 $\mu \mathrm{m}$, was obtained from J. Rettenmaier \& Söhne $\mathrm{GmbH}$ CoKG (Germany). The chain extender (CE) was Joncryl 4368 (BASF). PLA and PBS were dried at $100{ }^{\circ} \mathrm{C}$ for $4 \mathrm{~h}$ before processing to remove moisture.

\section{Sample preparation}

PLA and PBS (70/30 ratio) were blended with wood flour $(10,20,30 \% \mathrm{v} / \mathrm{v})$ and the chain extender $(1.0 \%)$. CE was used as interfacial modifier to enhance the adhesion between the polymer blend and the wood flour. All the materials were plasticized and blended in a Haake PolyDrive (from Thermo Fisher Scientific, USA) mixer (temperature of $180^{\circ} \mathrm{C}$, rotor speed of 50 rpm, for $3 \mathrm{~min}$ ).

The samples for mechanical tests were prepared using an injection molding machine (PROMA, Poland) at a temperature of $190{ }^{\circ} \mathrm{C}$.

\section{Mechanical properties}

Tensile properties were tested at a speed of 50 $\mathrm{mm} / \mathrm{min}$ by using a LLOYD LR10K machine (from Lloyd Instruments, USA), following ISO 527 standard. Samples of $4.0 \mathrm{~mm} \times 2.0 \mathrm{~mm}$ were used for the study. Impact tests were carried out using a Charpy impact tester (CEAST RESIL 5.5 from CEAST Italy). The pendulum speed was about $3.5 \mathrm{~m} / \mathrm{s}$ and the energy was of $4 \mathrm{~J}$ (ISO 179-2). The dimensions of the test samples were as follows: $10 \mathrm{~mm}$ x $4.0 \mathrm{~mm}$. Each measurement series consisted of 7 samples.

\section{Melt rheology}

Tests were performed using a Rheostress 6000 rotary rheometer from Thermo Fisher Scientific, equipped with a plate to plate sensor in the oscillatory mode. It was used to obtain the complex viscosity $\left(\eta^{*}\right)$, storage modulus (G') and loss modulus (G') values in the angular velocity range (0.06-250 $\mathrm{rad} / \mathrm{s})$. Samples were prepared by press molding of the composites to 1 $\mathrm{mm}$ thick plates of $25 \mathrm{~mm}$ diameter. The tests were performed at the temperature of $160{ }^{\circ} \mathrm{C}$.

\section{Thermal properties}

Differential scanning calorimetry (DSC Q20, TA Instruments, USA) was used to investigate the thermal properties, following ISO 11357-5 standard. The thermal ramp was from $40^{\circ} \mathrm{C}$ up to $200{ }^{\circ} \mathrm{C}$, at the rate of $10{ }^{\circ} \mathrm{C} \mathrm{min}^{-1}$ under nitrogen flow. The cooling rate was set to $-5^{\circ} \mathrm{C} \mathrm{min}^{-1}$.

\section{Morphology}

The morphology of all the materials was characterized using scanning electron microscopy (VEGA3 LM, TESCAN, USA). The freeze-fractured surface of PLA samples was observed. Sputtering with gold (Sputter Coater Cressington 108) was performed prior to SEM observation. An accelerating voltage of 5 $\mathrm{kV}$ was used. VegaTC software was employed for image analysis.

\section{Water absorption}

The water uptake of the samples was determined for each tested material. Three specimens of each material were weighed with accuracy to $0.1 \mathrm{mg}$. All the samples were immersed in sterile distilled water and incubated at a temperature of $23{ }^{\circ} \mathrm{C}$. For the measurements of weight, the samples were taken out of the water, the surfaces were dried with tissue paper and then weighed again. The measurements of weight were done in time geometric sequence (after 24, 48, 96, 192, etc. hours) until the samples reached saturation.

\section{RESULTS AND DISCUSSION Mechanical properties}

The most important parameters that allow characterizing the behavior of the samples, such as Young's modulus, stress at break and percentage strain at break during tensile testing, have been determined.

Mechanical test results are presented in Figure 1. PLA presents a Young's modulus value of about $2900 \mathrm{MPa}$ and PBS - of only $760 \mathrm{MPa}$. A slightly lower value was obtained for the 
PLA/PBS blend than for the PLA matrix, however, compared to pure PBS, it is three times higher. The addition of $\mathrm{CE}$ to the mixture caused a decrease in the value of the modulus, thus indicating that the presence of the chain extender did not provide an effective reinforcement. The addition of wood flour affects the increase in the value of elasticity modulus, depending on its contribution to the composite. The values of Young's modulus increase with an increasing amount of WF. An addition of $30 \mathrm{wt} \% \mathrm{WF}$ to the composite caused an increase to $3774 \mathrm{MPa}$ and $3938 \mathrm{MPa}$ for the composite containing CE. The presence of $\mathrm{CE}$ in the composites with wood flour did not significantly affect Young's modulus. As can be seen in Figure 1, there is no relationship between the addition of $\mathrm{CE}$ to individual composites and their Young's modulus.

In the case of stress at break (Fig. 2), it can be seen that one of the highest values (74.1 MPa) was obtained for PLA and the lowest value (16 $\mathrm{MPa}$ ) for the PLA/PBS blend. However, the addition of $\mathrm{CE}$ increases the stress at break value to $31.6 \mathrm{MPa}$. The addition of wood flour to the composites resulted in a significant increase in

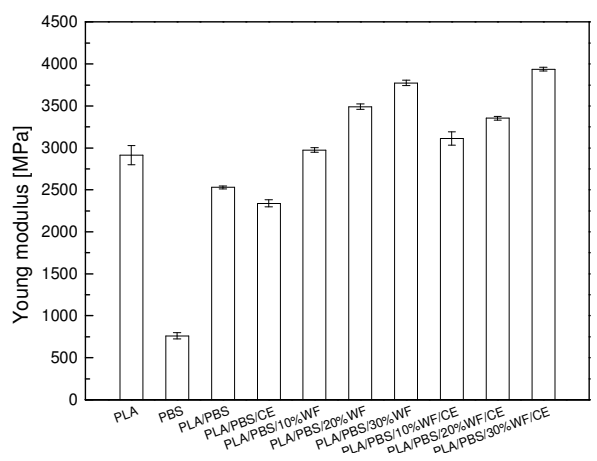

Figure 1: Young's modulus results

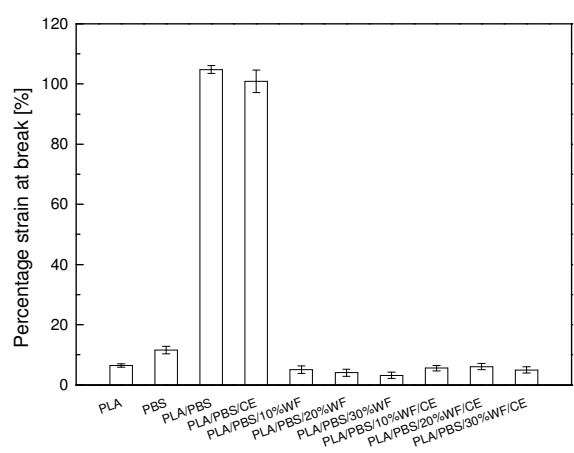

Figure 3: Percentage strain at break results stress at break, as compared to the PLA/PBS blend. It can be assumed that the amount of wood flour in the composite does not affect this value, as similar results (about $60 \mathrm{MPa}$ ) were obtained for 10, 20 and $30 \mathrm{wt} \%$ contents of WF in the composites. The addition of $\mathrm{CE}$ to the composites, in each case, resulted in an increase in the stress at break, where the composites with 20 and $30 \mathrm{wt} \%$ wood flour obtained the closest value to the one of the PLA matrix.

It has to be noted that the strain at break value measured for the PLA/PBS blend without WF addition, is significantly higher, reaching almost $100 \%$, compared to that of any other prepared material (Fig. 3). The addition of wood flour caused composites to break almost immediately under the applied load. The addition of WF affects the brittleness of composites. However, analyzing the results obtained for the composites filled with WF, an increase in strain at break after the addition of CE was observed. Therefore, it can be concluded that the addition of CE decreases the negative impact of WF on the material's mechanical properties.

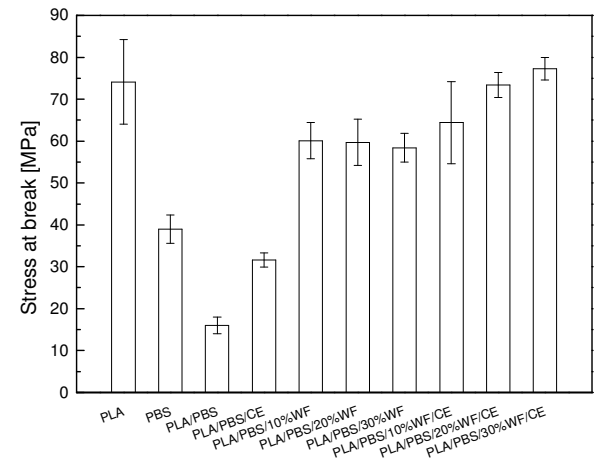

Figure 2: Stress at break results

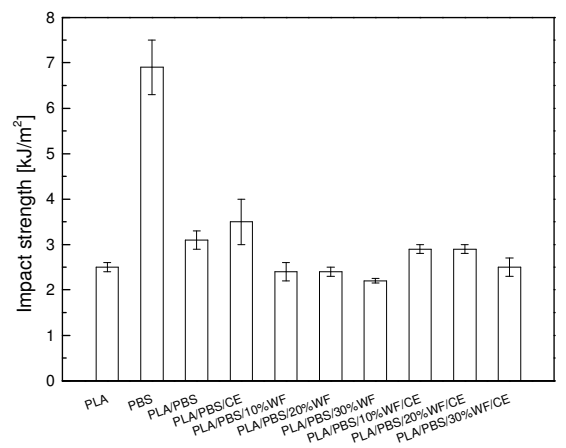

Figure 4: Impact strength results 
As can be seen in Figure 4, PBS is characterized by the highest impact strength (7.0 $\mathrm{kJ} / \mathrm{m}^{2}$ ). The addition of wood flour caused deterioration of the impact strength of composites, while the addition of $\mathrm{CE}$ had the opposite effect. The PLA/PBS blend, with and without the addition of $C E$, has a higher impact resistance, compared to the PLA matrix. It is also noteworthy that the PLA/PBS/WF composites, with the addition of $\mathrm{CE}$, have a higher impact value compared to PLA.

\section{Melt rheology}

The results of the rheology measurements are presented as a function of angular velocity at 160 ${ }^{\circ} \mathrm{C}$.

Complex viscosity curves for the base polymers, their blend and the blend mixed with $\mathrm{CE}$ are shown in Figure 5. PBS exhibited the lowest viscosity value among the tested materials, while PLA showed viscosity values higher by about one order of magnitude. An expected plateau for PLA and PBS in the lower velocity range indicates the absence of degradation.

The PLA/PBS blend (70/30 ratio) showed a viscosity value in between those of the neat polymers, which indicates that, at this polymer ratio, the blend is at least partially miscible. Adding CE had a significant effect on complex viscosity. An increase in viscosity was observed in the entire investigated angular velocity range. For the blend with $\mathrm{CE}$, the effect is clearly visible along with the typical shear thinning characteristics, a decrease of viscosity with increasing angular velocity (shear rate). When compared with the complex viscosity of the unmodified PLA/PBS blend, the enhanced viscosity indicates that macromolecular chain extension had occurred during the compounding process. $^{20}$

The complex viscosity curves of the PLA/PBS blend, PLA/PBS modified with CE and the blends with different wood flour content $(10,20,30 \%$ v/v) are presented in Figure 6. It can be observed that the viscosity increases with the addition of the chain extender, increasing wood flour content and decreases with angular velocity. As the complex viscosity represents the viscoelastic resistance of the polymer melt during the flow, the change is more visible at low shear rates, when along with the angular velocity increase and occurring shear thinning, the differences in viscosity become less explicit. The insolubility of the filler, in this case WF, is responsible for the increasing friction of the composite during the flow. One has to also keep in mind that WF particles are significantly more rigid when compared to the polymer blend, even with the added chain extender, therefore, they may disturb the flow, causing further increase in viscosity. ${ }^{21}$ With the higher shear rate, the viscous properties of the polymer matrix tend to play a secondary role, which results in the decrease of composite viscosity. ${ }^{22}$

Additional insight into the matrix/filler interaction and filler percolation can be obtained from comparing the modulus curves. At lower shear rates, all the investigated materials exhibited a predominantly viscous response, which was expected. To assess the polymer particle interactions, the crossover point analysis serves as a useful tool (determining the point at which one of the moduli becomes larger than the other - as the polymer response changes from viscous to solid elastic (G'>G'), or the other way around). As can be observed, PBS does not present a crossover point in the investigated angular velocity range, with a dominant viscous response at the applied load $\left(G^{\prime}>G^{\prime}\right)$. A similar response can be observed for PLA and the PLA/PBS blend, although in the highest velocity range the nearly $G^{\prime}=G^{\prime}$ 'tendency is visible. The presence of chain extender moves the crossover point to the lower velocity range (ca. $13 \mathrm{rads}^{-1}$ ), where due to improved macromolecular interaction, the material molecular or inter particle forces are larger than the force applied. 


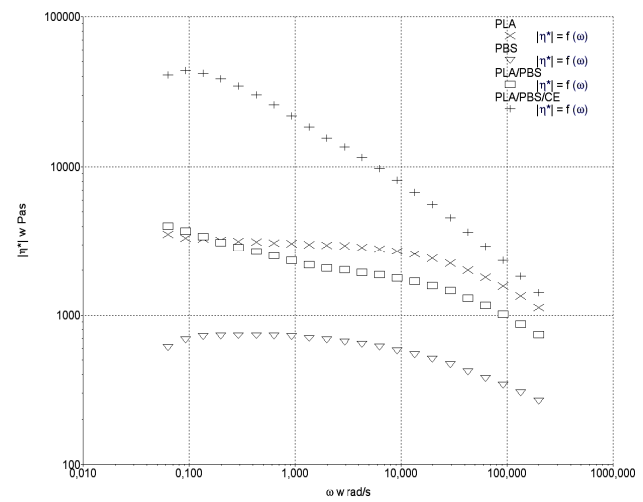

Figure 5: Complex viscosity of PLA/PBS blends

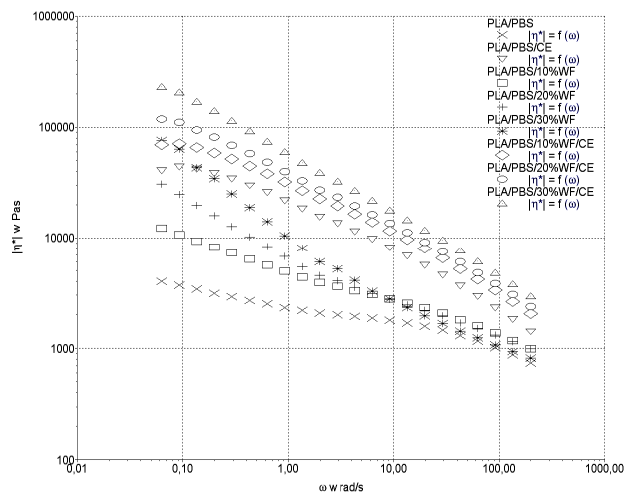

Figure 7: Storage modulus G' and loss modulus G" of PLA/PBS blends

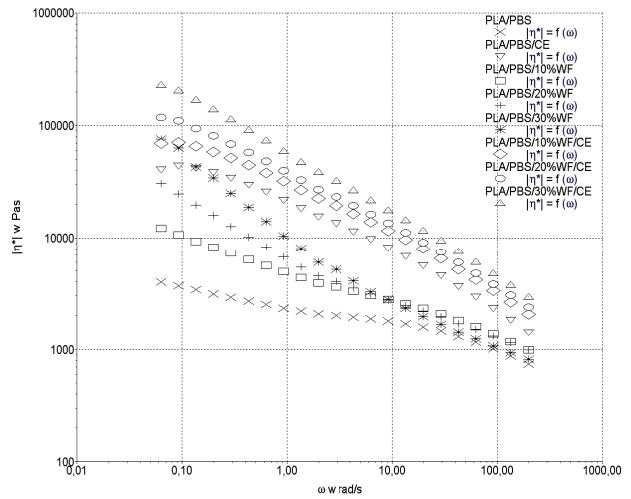

Figure 6: Complex viscosity of PLA/PBS/WF blends

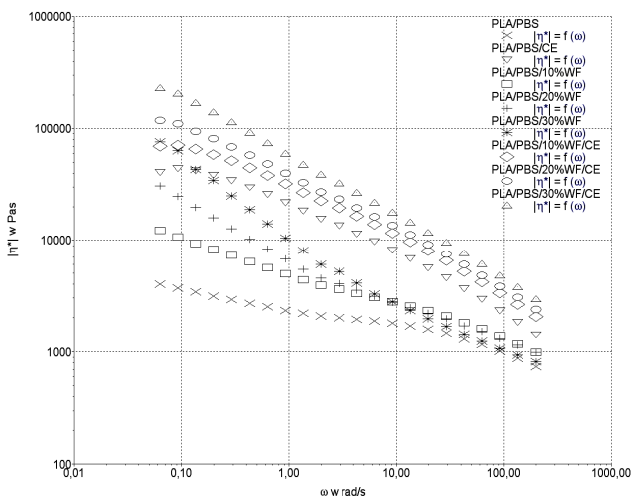

Figure 8: Storage modulus G' and loss modulus G" of PLA/PBS/WF blends

Table 1

DSC results

\begin{tabular}{lcccccccc}
\hline Sample & $T_{g}\left({ }^{\circ} \mathrm{C}\right)$ & $T_{m 1}\left({ }^{\circ} \mathrm{C}\right)$ & $T_{m 2}\left({ }^{\circ} \mathrm{C}\right)$ & $T_{m 3}\left({ }^{\circ} \mathrm{C}\right)$ & $T_{c l}\left({ }^{\circ} \mathrm{C}\right)$ & $T_{c 2}\left({ }^{\circ} \mathrm{C}\right)$ & $T_{c c l}\left({ }^{\circ} \mathrm{C}\right)$ & $T_{c c 2}\left({ }^{\circ} \mathrm{C}\right)$ \\
\hline PLA & 61.7 & - & 149.9 & 154.9 & - & - & - & 113.0 \\
PBS & -30.0 & 101.0 & - & - & - & 115.1 & 80.0 & - \\
PLA/PBS & 59.0 & - & 114.7 & 149.1 & 65.7 & 86.4 & 95.0 & 119.3 \\
PLA/PBS/CE & 59.3 & - & 114.2 & 149.4 & 69.8 & 87.1 & 98.4 & 121.5 \\
PLA/PBS/10\%WF & 60.0 & 106.5 & 115.1 & 151.3 & 71.9 & 91.3 & 90.9 & 121.2 \\
PLA/PBS/20\%WF & 58.8 & 104.7 & 114.8 & 149.2 & 74.4 & 89.0 & 109.0 & 119.1 \\
PLA/PBS/30\%WF & 59.2 & 104.3 & 114.2 & 150 & 72.5 & 88.3 & 108.1 & 120.1 \\
PLA/PBS/10\%WF/CE & 59.6 & - & 114.7 & 150.0 & 73.4 & 87.8 & 98.7 & 123.3 \\
PLA/PBS/20\%WF/CE & 60.0 & - & 115.5 & 151.5 & 73.2 & 88.0 & 89.9 & 127.6 \\
PLA/PBS/30\%WF/CE & 60.4 & - & 114.8 & 151.6 & 71.3 & 88.5 & 90.5 & 130.2 \\
\hline
\end{tabular}

\section{Thermal properties}

The DSC results are presented in Table 1. PLA is characterized by $T_{g}$ equal to $61.7{ }^{\circ} \mathrm{C}$, two melting temperatures of 149.9 and $154.9^{\circ} \mathrm{C}$, and the temperature of cold crystallization of $113{ }^{\circ} \mathrm{C}$. PBS has a much lower $T_{g}=-30{ }^{\circ} \mathrm{C}, T_{m}=101{ }^{\circ} \mathrm{C}$ and $T_{c}=115.1$ and $T_{c c}=80^{\circ} \mathrm{C}$.
For the PLA/PBS blends, corresponding to the glass transition temperature of PLA $\left(59^{\circ} \mathrm{C}\right)$, two melting points $\left(114.7,149.1{ }^{\circ} \mathrm{C}\right)$, crystallization $\left(65.7 ; 86.4{ }^{\circ} \mathrm{C}\right)$ and cold crystallization temperatures $\left(95{ }^{\circ} \mathrm{C} ; 119.3{ }^{\circ} \mathrm{C}\right)$ were noted. Two separate signals corresponding to the melting temperature indicate the immiscibility of both polymers. 
The thermal properties of the PLA/PBS blend were not affected by CE. Three melting points for the PLA/PBS composites, with the addition of WF, were noted. The $T_{m 2}$ and $T_{m 3}$ values are correlated with the melting points obtained for the polymer blend. $T_{m l}$ adopts lower values (104-107 ${ }^{\circ} \mathrm{C}$ ) and does not appear on the heating curves for the composites with CE additive. The PLA/PBS blend is characterized by two $T_{c}$ temperatures, similar to the PLA/PBS composites with and without the addition of CE. The content of WF and CE did not affect significantly the $T_{m}$ and $T_{c}$ of the composites. However, for all the composites, the $T_{c 1}$ and $T_{c 2}$ values are higher by a few degrees, compared to those of the PLA/PBS blend. $T_{c c 1}$ and $T_{c c 2}$ temperatures for all the blends and the composites have higher values, compared to those of the PLA and PBS matrices, respectively.

\section{Morphology}

Microscopic images of PLA, PBS, the PLA/PBS blend and the composites filled with WF and CE are presented in Figure 9. As the content of wood flour increases, the surface of the composites becomes more uneven. WF used does not form a standard shape and its geometry varies, unlike other commonly used fillers (i.e. carbon fibres). This is associated with the natural origin of the WF, considered as a group of cellulose fibrils connected by other components (lignin, waxes and other).

It has also been noted that doping the composite with a higher amount of WF will loosen the structure of the composites. The analysis of the microscopic images indicates that $\mathrm{WF}$, regardless of its content in the composites, has been well distributed in the polymer matrix, as evidenced by the lack of agglomerates. Some small holes caused by detaching wood flour from the composites can be observed, which may indicate poor polymer-filler interaction. The addition of $\mathrm{CE}$ to the materials changes the surface of the fractures, making it smoother and more homogeneous, without obvious plastic deformation. Moreover, it seems that the composites with the addition of $\mathrm{CE}$ are characterized by better interfacial adhesion.

\section{Water absorption}

Humidity and the presence of water are important for decomposition processes, such as hydrolysis, and are fundamental for biodegradation in enzymatic reactions involving microorganisms. Therefore, we tested the water uptake of the components PLA, PBS, PLA/PBS, PLA/PBS/CE and of the blends with wood fibers. In 8 weeks' time, all the tested samples were saturated.

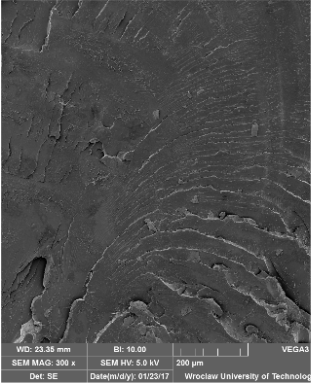

PLA

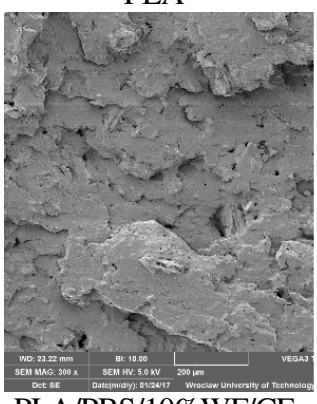

PLA/PBS/10\%WF/CE

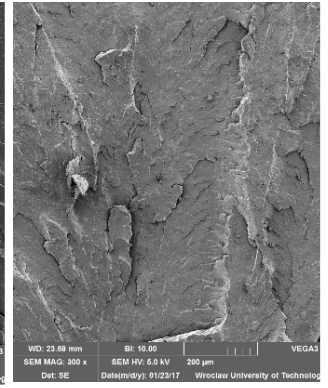

PBS

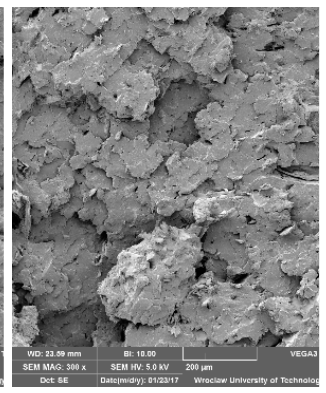

PLA/PBS/20\%WF
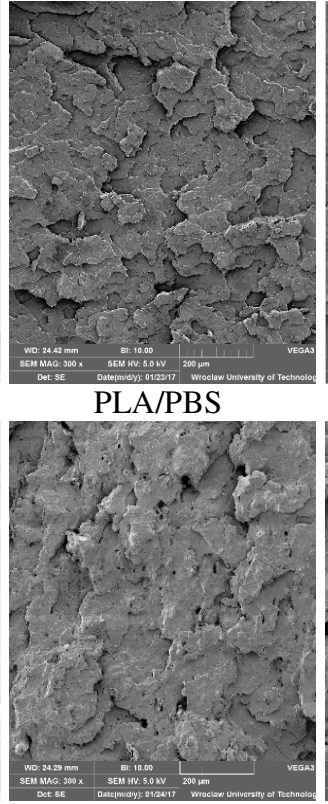

PLA/PBS/20\%WF/CE

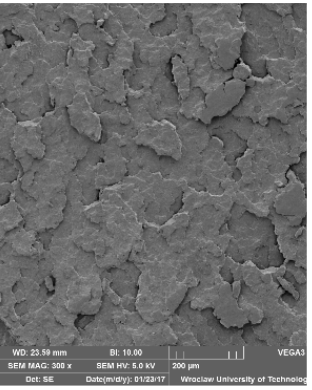

PLA/PBS/CE

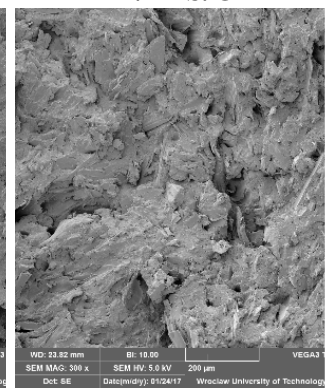

PLA/PBS/30\%WF

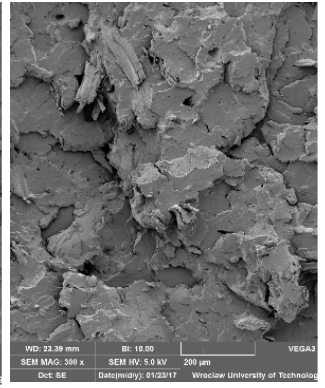

PLA/PBS/10\%WF

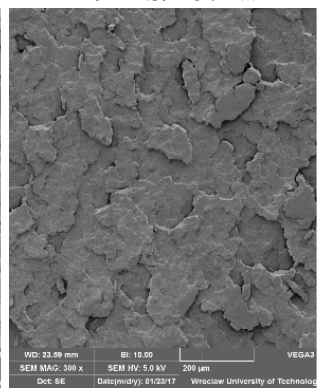

PLA/PBS/30\%WF/CE

Figure 9: SEM images 


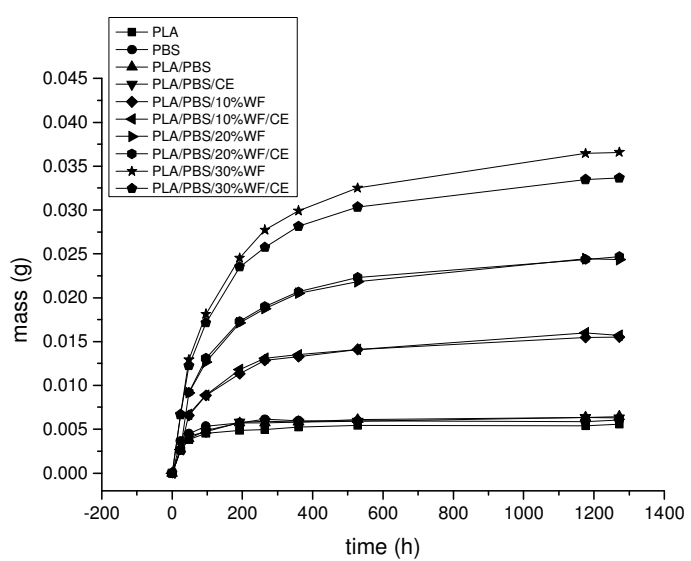

Figure 10: Water absorption

Strong water absorption was observed only for the blends with wood fibers and the amount of the water uptake increased as the amount of WF in the blend increased. It seems that the uptake of water by materials with 10 and $20 \%$ WF addition is not affected by the presence of CE, the blends with and without $\mathrm{CE}$ have the same ability to absorb water. However, the composite with $30 \%$ WF and without CE shows slightly stronger water absorption than that with added CE.

The content of wood fibers in the new blends, due to their ability to absorb water, will have an impact on the durability, biodegradability, as well as storage and transport conditions of the tested composites.

\section{CONCLUSION}

A PLA/PBS (70/30) system was prepared to investigate the influence of adding wood flour and a chain extender on its properties. The elasticity and tensile strength of the unfilled blend followed the general trend of the mixture. The addition of wood flour improved the mechanical properties (comparing to those of the unmodified blend), which reached the highest values after incorporation of the chain extender.

Macromolecular chain extension was proved by rheological tests, showing that viscosity had increased. A slight improvement of the interaction force between PLA and PBS was observed by SEM investigation. Also, a crossover point shift to the lower velocity range was established.

Changes in the water absorption rate followed the above-mentioned tendencies. An increase of this parameter is consistent with wood flour loading, a slight increase can also be observed in the samples containing chain extender.
ACKNOWLEDGMENTS: This work was supported by an internal financing mechanism, agreement no. 049M/0005/19.

\section{REFERENCES}

1 A. Iwatake, M. Nogi and H. Yano, Compos. Sci. Technol. 68, 2103 (2008), https://doi.org/10.1016/j.compscitech.2008.03.006 2 R. Zhu, H. Liu and J. Zhang, Ind. Eng. Chem. Res., 51, 7786 (2012), https://doi.org/10.1021/ie300118x

3 A. Bhatia, R. K. Gupta, S. N. Bhattacharya and H. J. Choi, Int. Polym. Process, 25, 5 (2010), https://doi.org/abs/10.3139/217.2214

4 C. Nyambo, A. K. Mohanty and M. Misra, Macromol. Mater. Eng., 296, 710 (2011), https://doi.org/10.1002/mame.201000403

5 A. Araújo, G. Botelho, M. Oliveira and A. V. Machado, Appl. Clay Sci. 88, 144 (2014), https://doi.org/10.1016/j.clay.2013.12.005

6 A. N. Frone, S. Berlioz, J. F. Chailan and D. M. Panaitescu, Carbohyd. Polym., 91, 377 (2013), https://doi.org/10.1016/j.carbpol.2012.08.054

7 J.-M. Raquez, Y. Habibi, M. Murariu and P. Dubois, Prog. Polym. Sci., 38, 1504 (2013), https://doi.org/10.1016/j.progpolymsci.2013.05.014

8 A. C. Fowlks and R. Narayan, J. Appl. Polym. Sci., 118, 2810 (2010), https://doi.org/10.1002/app.32380

9 R. M. Taib, Z. A. Ghaleb and Z. A. M. Ishak, $J$. Appl. Polym. Sci., 123, $2715 \quad$ (2012), https://doi.org/10.1002/app.34884

10 E. A. Hassan, S. E. Elarabi, Y. Wei and M. Yu, Text. Res. J., $\mathbf{8 8 ,} 1735 \quad$ (2018), https://doi.org/10.1177/0040517517708538

11 A. Bhatia, R. Gupta, S. Bhattacharya and H. Choi, Korea-Aust. Rheol. J., 19, 125 (2007), http://researchbank.rmit.edu.au/view/rmit:3381

12 A. Bourmaud, D. Åkesson, J. Beaugrand, A. Le Duigou, M. Skrifvars et al., Polym. Degrad. Stabil., 128, 77 (2016), https://doi.org/10.1016/j.polymdegradstab.2016.03.018 
13 T. Yokohara and M. Yamaguchi, Eur. Polym. J., 44, 677

(2008),

https://doi.org/10.1016/j.eurpolymj.2008.01.008

14 S. Chuayjuljit, C. Wongwaiwattanakul, P. Chaiwutthinan and P. Prasassarakich, Polym. Compos., 38, 2841 (2017), https://doi.org/10.1002/pc.23886

15 R. Homklin and N. Hongsriphan, Energy Procedia, 34, 871 (2013),

https://doi.org/10.1016/j.egypro.2013.06.824

16 M. Harada, T. Ohya, K. Iida, H. Hayashi, K. Hirano et al., J. Appl. Polym. Sci., 106, 1813 (2007), https://doi.org/10.1002/app.26717

17 S. B. Park, S. Y. Hwang, C. W. Moon, S. S. Im and E. S. Yoo, Macromol. Res., 18, 463 (2010), https://doi.org/10.1007/s13233-010-0512-2
18 B. S. Westerlind, J. Appl. Polym. Sci., 36, 523 (1988), https://doi.org/10.1002/app.1988.070360306

19 P. Chaiwutthinan, T. Leejarkpai, D. P. Kashima and S. Chuayjuljit, Adv. Mater. Res., 664, 644 (2013), https://doi.org/10.4028/www.scientific.net/AMR.664.6 44

20 L. C. Arruda, M. Magaton, R. E. S. Bretas and M. M. Ueki, Polym. Test., 43, 27 (2015), https://doi.org/10.1016/j.polymertesting.2015.02.005

21 V. Mazzanti, Polym. Compos., 37, 3460 (2016), https://doi.org/10.1002/pc.23546

22 W. Frącz and G. Janowski, Wood Res., 63, 14 (2018), http://www.woodresearch.sk/wr/201802/13.pdf 